\title{
Microstructure of Milled Polyacrylonitrile-Based Carbon Fiber Analyzed by Micro-Raman Spectroscopy and TEM
}

\author{
Sang-Hye Lee ${ }^{1}\left(\mathbb{D}\right.$, Sang-Min Lee ${ }^{2}$ and Jae-Seung Roh $^{1, *}$ \\ 1 School of Materials Science and Engineering, Kumoh National Institute of Technology, 61 Daehak-ro, \\ Gumi 39177, Korea; shlee3106@kumoh.ac.kr \\ 2 Carbolab Co., Ltd., Gumi 39425, Korea; dltkdals3232@hanmail.net \\ * Correspondence: jsroh@kumoh.ac.kr
}

check for updates

Citation: Lee, S.-H.; Lee, S.-M.;

Roh, J.-S. Microstructure of Milled

Polyacrylonitrile-Based Carbon Fiber Analyzed by Micro-Raman Spectroscopy and TEM. Materials 2021, 14, 4711. https://doi.org/ $10.3390 / \mathrm{ma} 14164711$

Academic Editor: Ricardo J. C. Carbas

Received: 21 July 2021

Accepted: 18 August 2021

Published: 20 August 2021

Publisher's Note: MDPI stays neutral with regard to jurisdictional claims in published maps and institutional affiliations.

Copyright: (c) 2021 by the authors. Licensee MDPI, Basel, Switzerland. This article is an open access article distributed under the terms and conditions of the Creative Commons Attribution (CC BY) license (https:// creativecommons.org/licenses/by/ $4.0 /)$.
Abstract: Milled polyacrylonitrile (PAN)-based Carbon Fibers (mPCFs) were prepared from PANbased carbon fibers by using a ball milling process. The resulting structural changes in the mPCFs were analyzed by correlating the analytical results obtained by X-ray diffraction (XRD) and Raman spectroscopy and verified by transmission electron microscopy (TEM) lattice images and diffraction patterns. The crystallite size $L_{a}$ calculated from the XRD measurements decreased as the milling time was increased to $12 \mathrm{~h}$ and then decreased as the milling time was further increased to $18 \mathrm{~h}$. The La of both partially-milled Carbon Fiber (pmCF) and milled Carbon Fiber (mCF) calculated from the Raman spectroscopy data continuously increased as the milling time increased. The difference may be because XRD measured the entire sample regardless of pmCF and $\mathrm{mCF}$, while Raman spectroscopy was limited to measuring the surface and differentiated pmCF and mCF. As the ball milling time increased, the fiber surface was firstly broken by the impact energy of the balls, decreasing crystallinity, while the La inside the unbroken fibers increased.

Keywords: crystallinity; milled carbon fiber; PAN-based carbon fiber; Raman; XRD

\section{Introduction}

Milled Carbon Fiber (mCF) is a type of carbon fiber with a filament shorter than chopped carbon fiber, typically a length of $1 \mathrm{~mm}$ or less [1]. The $\mathrm{mCF}$ is generally made from polyacrylonitrile (PAN) and mesophase pitch carbon fibers using various pulverizing methods (ball mill, melt blown, mechanical grinding, etc.). Milled mesophase pitch-based carbon fiber has been studied for application as an anode material in Li-ion batteries [2], and milled PAN-based Carbon Fiber (mPCFs) is mainly used as a filler for polymer composite materials for increasing their conductivity [3-7]. Most studies on mPCFs have focused on their electric conductivity, which depends on the filament length and amount when used as a filler for polymer composite materials [3-8]. However, little has been reported about their crystallinity, which is the most important factor affecting electric conductivity.

M. Endo [2] prepared milled mesophase pitch-based carbon fiber by melt-blow and analyzed its crystallinity using XRD and Raman spectroscopy. The XRD results showed that the $d_{002}$ and $L_{c}$ increased as the thermal treatment temperature increased. The Raman analysis showed that $R\left(=I_{1360} / I_{1580}\right)$ decreased and the crystallite $L_{a}$ increased as the thermal treatment temperature increased. Based on these results, M. Endo reported that the crystallinity of milled mesophase pitch-based carbon fiber could be effectively analyzed by XRD and Raman spectroscopy.

Tuinstra and Koening [9] firstly reported the correlation between $R$ and crystallite size $L_{a}$ using the peak intensity at 1360 and $1580 \mathrm{~cm}^{-1}$ by using Raman scattering-based methods for characterizing graphite. After their study, Raman spectroscopy has become one of the most important analytical methods for studying the structural characteristics of carbon and graphite [10-12]. 
In our previous studies, we prepared mPCFs by varying the ball milling time and then analyzed the crystallinity and electrical conductivity with XRD [13]. The asymmetric (002) peak was deconvoluted into two peaks: one for less-developed crystalline carbon (LDCC) and the other more-developed crystalline carbon (MDCC). After milling, the Lc of both LDCC and MDCC was lower, the $d_{002}$ was higher, and the LDCC fraction had also increased. In other words, the XRD results showed that $\mathrm{mPCF}$ became more amorphous as the milling time was increased.

We conducted the present study in order to investigate the crystallinity of mPCFs according to milling time by using Raman spectroscopy and analyzed the results in association with the XRD results. Changes in the crystallinity of the MPCFs were also verified by transmission electron microscopy (TEM).

\section{Experimental}

\subsection{Sample Preparation}

The starting carbon fiber used in the present study was PAN-based carbon fiber T700 (12 K) manufactured by Toray, Tokyo, Japan. The starting carbon fiber was inserted to a tube furnace in nitrogen atmosphere and kept at $500^{\circ} \mathrm{C}$ for $1 \mathrm{~h}$ to remove the sizing agent. In the present study, all of the ball milling processes were performed using the desized carbon fiber.

\subsection{Ball Milling and Shape Observation}

The desized carbon fiber was cut to $20 \mathrm{~mm}$ and milled at $300 \mathrm{rpm}$ using alumina balls $(99.94 \%)$. The milling times were varied to 6,12 , and $18 \mathrm{~h}$. During milling, some of the fibers that were not pulverized became aggregated and formed fiber balls, which are continuously packed and decreaseed pulverization efficiency. To avoid this, the mPCFs were enmeshed through a 230-mesh (under $63 \mu \mathrm{m}$ ) and prepared as sorted fine fibrous powder.

After ball milling for 6,12 and $18 \mathrm{~h}$, the particle size of the mPCFs $\left(D_{50}\right)$ decreased to $10.63 \mu \mathrm{m}, 3.25 \mu \mathrm{m}$, and $1.83 \mu \mathrm{m}$, respectively. Figures 1 and 2 show the SEM images of the $\mathrm{mPCFs}$ depending on the ball milling time.

The mPCFs shown in Figure 1 include partially-milled Carbon Fiber (pmCF, solid line), which retains the surface and cross-sectional shape of a conventional fiber, and milled Carbon Fiber ( $\mathrm{mCF}$, dotted line) that has been completely pulverized and has lost the fibrous shape. After $6 \mathrm{~h}$ of milling time, the mPCFs were mostly pmCF. The ratio of pmCF decreased and that of $\mathrm{mCF}$ increased as the milling time was increased.

Figures 1 and 2 show that a portion of the pmCF that was milled for $12 \mathrm{~h}$ had a complete fibrous shape (Figure 1c), but most of the pmCF had the shape of broken fibers (Figure 2c). The SEM images of the sample that was milled for $18 \mathrm{~h}$ showed no pmCF with a complete fibrous shape, and all the fibers were broken.

The 10,000 enlarged images in Figure 2 shows that the surface of the fiber was broken after $12 \mathrm{~h}$, and $\mathrm{mCF}$ particles attached to the $\mathrm{pmCF}$ were observed. Since the $\mathrm{mPCF}$ were found to be a mixture of fiber and powder, the measurements were performed by differentiating pmCF from $\mathrm{mCF}$ by using the optical images obtained from the Raman analysis.

\subsection{X-ray Diffraction and Conductivity}

The crystallinity dependence on ball milling time was analyzed by XRD (X-MAX/2000$\mathrm{PC}$, Rigaku). The wavelength of the X-ray target $\left(\mathrm{Cu}-\mathrm{K}_{\alpha 1}\right)$ used in the XRD analysis was $1.5406 \AA$, and the XRD spectrum was obtained by $2 \theta$ continuous scanning in a scan range of 10 to $60^{\circ}$ at a scan rate of $1^{\circ} / \mathrm{min}[13,14]$. The measurement was performed three times for each sample.

After removing the background, the (002) peak was separated into two bands (LDCC and MDCC) by Gaussian fitting in order to calculate $d_{002}$ and $L_{c}$. The $2 \theta$ and the full width at half maximum value obtained from each band and peak were used to calculate planar spacing using the Bragg equation, and the Lc and La were calculated with the Scherrer equation $[13,14]$. 

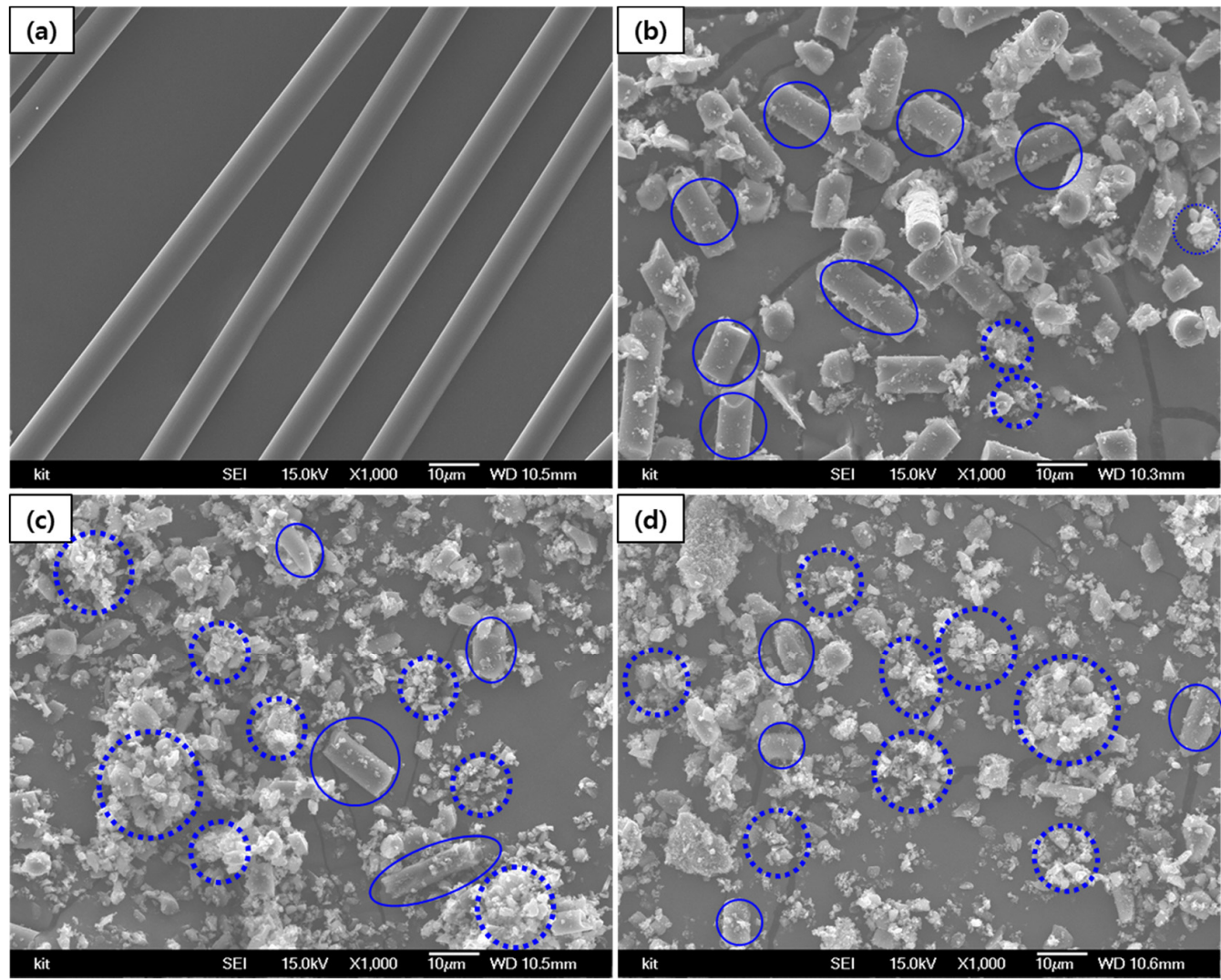

Figure 1. SEM images of mPCFs ( $\times 1000)$. (a) Desized carbon fiber and ball milling times of $(\mathbf{b}) 6 \mathrm{~h},(\mathbf{c}) 12 \mathrm{~h}$, and (d) $18 \mathrm{~h}$.
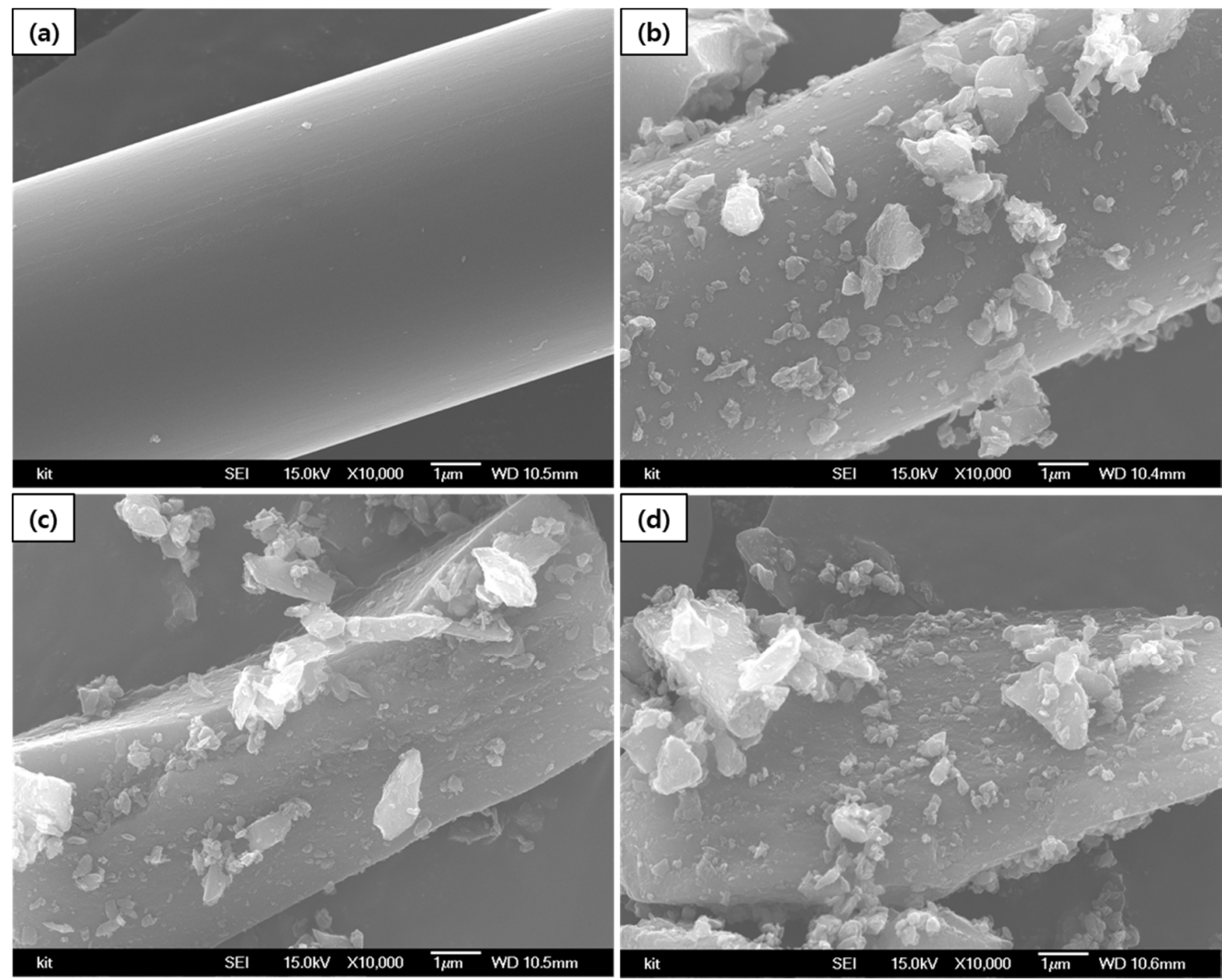

Figure 2. SEM images of mPCFs $(\times 10,000)$. (a) Desized carbon fiber and ball milling times of (b) $6 \mathrm{~h},(\mathbf{c}) 12 \mathrm{~h}$, and (d) $18 \mathrm{~h}$. 
The dependence of the electric conductivity of the mPCFs on the milling time was measured using a powder resistivity measurement system (HAN TECH Co. Ltd., Gunpo, Korea). Pulverized mPCF was packed into a mold possessing a diameter of $20 \mathrm{~mm}$, and the resistivity was measured by 4-point probe and converted into electric conductivity. R. Holm et al. $[15,16]$ explained that the electric conductivity of powder is lower than that of individual particles because the interface between particles introduces additional resistance when charges are transported. Applying pressure during the measurement of the electric conductivity of powder increases the electric conductivity, by increasing the contact area between particles. In the present study, the electric conductivity of the MPCF powder was measured by varying pressures between 1.29 and $51.6 \mathrm{MPa}$ in order to find the trend. In this paper, we used the measurement values obtained at 51.6 MPa.

\subsection{Raman Spectroscopy}

The crystallinity dependence on milling time was measured using a Raman spectroscopy (Raman, System 1000, Renishaw, Wotton-under-Edge, UK). Raman spectroscopy was performed with an Ar-ion laser at a wavelength of $541 \mathrm{~nm}$ [17].

Researchers have presented various values for the constant $C$ in the domain size of $L_{a}=(C / R)$ according to laser type and wavelength. Knight and White [18] employed an Ar-ion laser at a wavelength of $514.4 \mathrm{~nm}$ and calculated that the crystallite $L_{a}$ in a single crystal of graphite was (44/R). M. Endo [2] prepared milled mesophase pitch-based carbon fiber and analyzed the crystallinity by Raman spectroscopy with a HeNe laser at a wavelength of $632.8 \mathrm{~nm}$, reporting that the calculated crystallite $L_{a}$ was (120/R). Roh [19] analyzed the structure of activated carbon fiber by Raman spectroscopy with an Ar-ion laser at a wavelength of $514.5 \mathrm{~nm}$ and reported that the calculated $L_{a}$ was $(20 / R)$.

In the present study, we analyzed the change in crystallinity by measuring the peak intensity ratio, $R\left(=I_{D} / I_{G}\right)$, of the D-band at $1360 \mathrm{~cm}^{-1}$ relative to the G-band at $1580 \mathrm{~cm}^{-1}$ [11,17]. The intensity ratio of the peaks was calculated without modifying the baseline of the Raman spectra. We separately analyzed the surface crystallinity of the fine $\mathrm{mCF}$ powder and that of the $\mathrm{pmCF}$, which was not completely pulverized. The broken fibrous shapes observed in Figure 1; Figure 2c,d were all considered to be pmCFs, and the measurement was performed by ignoring the $\mathrm{mCF}$ attached to the pmCF surface. Three Raman spectra were obtained from each $\mathrm{pmCF}$ and $\mathrm{mCF}$, and their dispersions are presented.

\subsection{TEM}

The specimens used for TEM (JEOL, JEM, and 2100) analysis were prepared using the common method for preparing fiber specimens. The fibers were arranged in one direction, cured in an epoxy resin, and kept in a vacuum oven at $70{ }^{\circ} \mathrm{C}$ for $24 \mathrm{~h}$. After that, the resulting specimens were cut by using a diamond knife attached to Cryo-Ultramicrotome (RMC, PTPC\&CRX). The cut fiber specimens were mounted on a Cu-grid and observed at an acceleration voltage of $200 \mathrm{kV}$. The grid images were obtained at a magnification of 800,000 by under-focusing after determining the conditions under which the crystallite layers could be clearly viewed. We tried to observe the surface and the inside of the fiber specimens separately, but it was impossible because the sampling with the diamond knife was carried out randomly. The lattice images and the diffraction patterns (DP) were obtained at a magnification of 800,000 . We observed at least 3 points of a sample that were considered to be homogeneous [20,21]. Only the brightness and contrast of the images were adjusted without any special image processing.

\section{Results and Discussion}

\subsection{X-ray Diffraction and Conductivity}

Table 1 and Figure 3 show the change of the XRD structural factors of the mPCFs depending on the milling time. The values of the structural factors are the mean values of three measurements from each specimen. In the desized carbon fiber, the $d_{002}$ and $L_{\mathcal{C}}$ values 
at the LDCC band were $3.750 \AA$ and $12.77 \AA$, respectively, and those at the MDCC band were $3.466 \AA$ and $24.33 \AA$, respectively. As the milling time increased, the $d_{002}$ increased, and the $L_{c}$ decreased for both the LDCC and MDCC bands. After $18 \mathrm{~h}$ of milling time, the $d_{002}$ and $L_{c}$ values of the LDCC band were $3.804 \AA$ and $11.33 \AA$, respectively, and those of the MDCC band were $3.503 \AA$ and $23.47 \AA$, respectively. The La of the desized carbon fiber was $51.63 \AA$. With increasing milling time, it decreased to $50.27 \AA$ at $12 \mathrm{~h}$ and then increased to $52.70 \AA$ at $18 \mathrm{~h}[13]$.

Table 1. XRD structural factors of mPCFs depending on milling time [13].

\begin{tabular}{ccccccccc}
\hline $\begin{array}{c}\text { Milling } \\
\text { Time } \\
\text { (h) }\end{array}$ & \multicolumn{3}{c}{ 002 Peak (LDCC) } & \multicolumn{3}{c}{ 002 Peak (MDCC) } & \multicolumn{2}{c}{ 10l Peak } \\
\cline { 2 - 10 } & $\mathbf{2 \theta}$ & $\boldsymbol{d}_{\mathbf{0 0 2}}(\AA)$ & $\boldsymbol{L}_{\boldsymbol{c}}(\AA)$ & $\mathbf{2 \theta}$ & $\boldsymbol{d}_{\mathbf{0 0 2}}(\AA)$ & $\boldsymbol{L}_{\boldsymbol{c}}(\AA)$ & $\mathbf{2 \theta}$ & $\boldsymbol{L}_{\boldsymbol{a}}(\AA)$ \\
\hline 0 & 24.38 & 3.750 & 12.77 & 25.68 & 3.466 & 24.33 & 44.23 & 51.63 \\
\hline 6 & 23.43 & 3.793 & 11.57 & 25.45 & 3.497 & 23.67 & 43.68 & 50.47 \\
\hline 12 & 23.42 & 3.795 & 11.37 & 25.46 & 3.496 & 23.30 & 43.67 & 50.27 \\
\hline 18 & 23.37 & 3.804 & 11.33 & 25.40 & 3.503 & 23.47 & 43.50 & 52.70 \\
\hline
\end{tabular}

Table 2 shows the electric conductivity of the mPCFs measured by using the powder resistivity measurement system under a load of $51.6 \mathrm{MPa}$. The electric conductivity of the desized carbon fiber was $98.1 \mathrm{~S} / \mathrm{cm}$. As the milling time increased, the electric conductivity decreased to $6.54 \mathrm{~S} / \mathrm{cm}$ at $18 \mathrm{~h}$. The decrease in electric conductivity was greatest between 0 and $6 \mathrm{~h}$ of milling time. The ball milling process decreased the fiber length, and the reduction in internal crystallinity acted as defects, reducing the electric conductivity.

Table 2. Electric conductivity of mPCFs depending on milling time.

\begin{tabular}{|c|c|c|c|}
\hline Milling Time (h) & $\begin{array}{l}\text { Press } \\
\text { (MPa) }\end{array}$ & $\begin{array}{c}\text { VR } \\
(\Omega \cdot \mathrm{cm})\end{array}$ & $\begin{array}{c}\text { Conductivity } \\
(\mathrm{S} / \mathrm{cm})\end{array}$ \\
\hline 0 & \multirow{4}{*}{$\begin{array}{c}51.6 \\
(2000 \mathrm{~kg})\end{array}$} & 0.0102 & 98.1 \\
\hline 6 & & 0.0502 & 19.9 \\
\hline 12 & & 0.0924 & 10.8 \\
\hline 18 & & 0.1530 & 6.54 \\
\hline
\end{tabular}

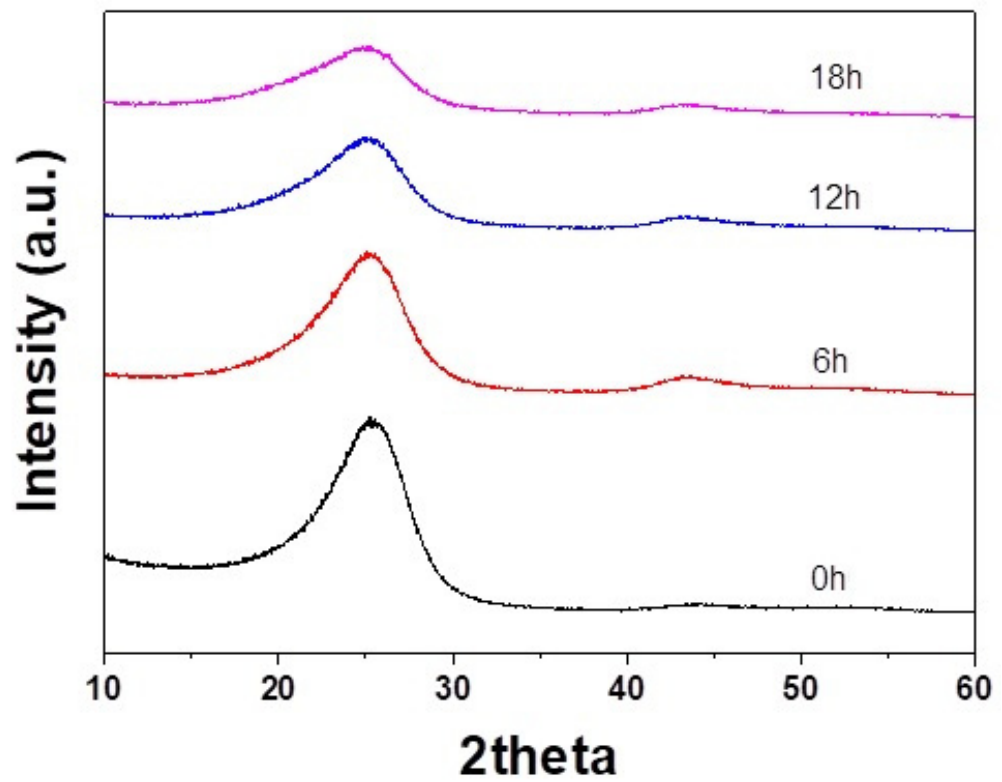

Figure 3. XRD patterns of mPCFs depending on milling time. 


\subsection{Raman Spectroscopy}

Figure 4 shows the Raman spectra of the pmCF and $\mathrm{mCF}$ depending on the milling time. As the milling time increased, the peak intensity of the G-band of the mCF decreased, while that of the D-band increased.

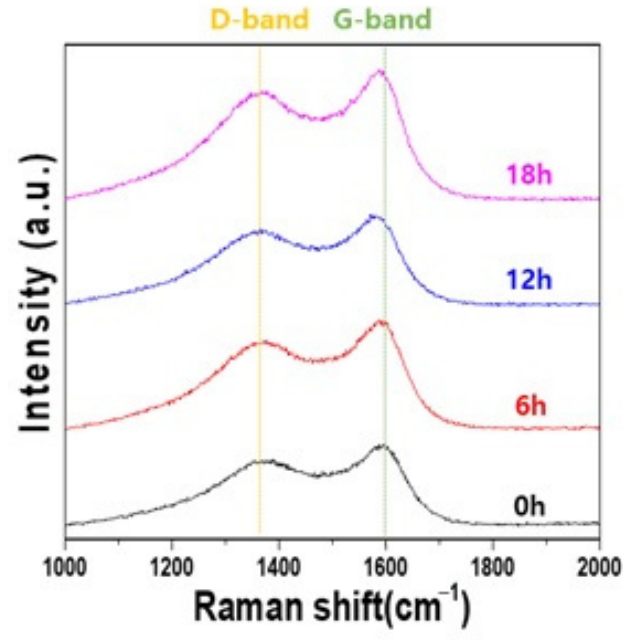

(a)

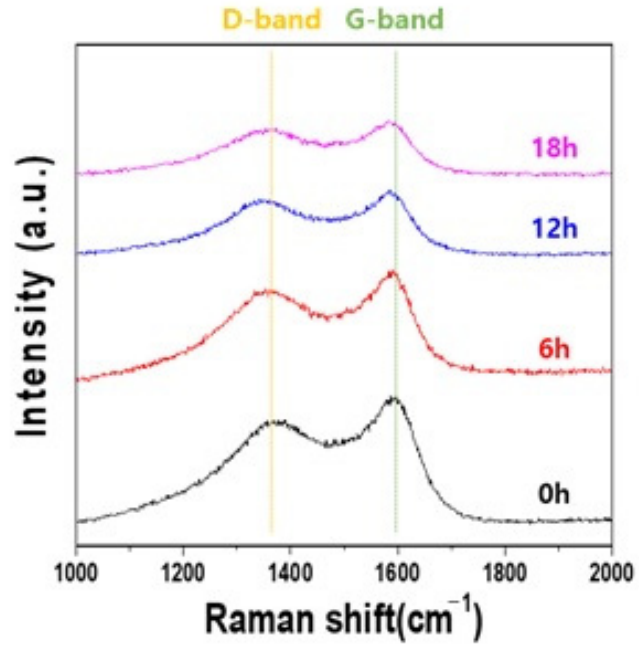

(b)

Figure 4. Raman spectra of mPCFs, (a) pmCF, and (b) mCF.

Figure 5 shows that the ball milling process affected the position of the Raman bands. In the G-band, the Raman peak positions of the pmCF and mCF were almost similarly shifted to a lower value. However, a closer look at the shift revealed a slight difference. At the milling time of $6 \mathrm{~h}$, the Raman band position of the pmCF, which still retained the complete shape, also shifted. At the milling time of $12 \mathrm{~h}$, the position shift of the milled pmCF was greater than that of $\mathrm{mCF}$. This suggests that slight disordering was also occurring on the surface of the pmCF that was not pulverized to powder and, thus, maintained a complete shape. The disordering may have been larger in the $\mathrm{mCF}$ that was further pulverized and broken.

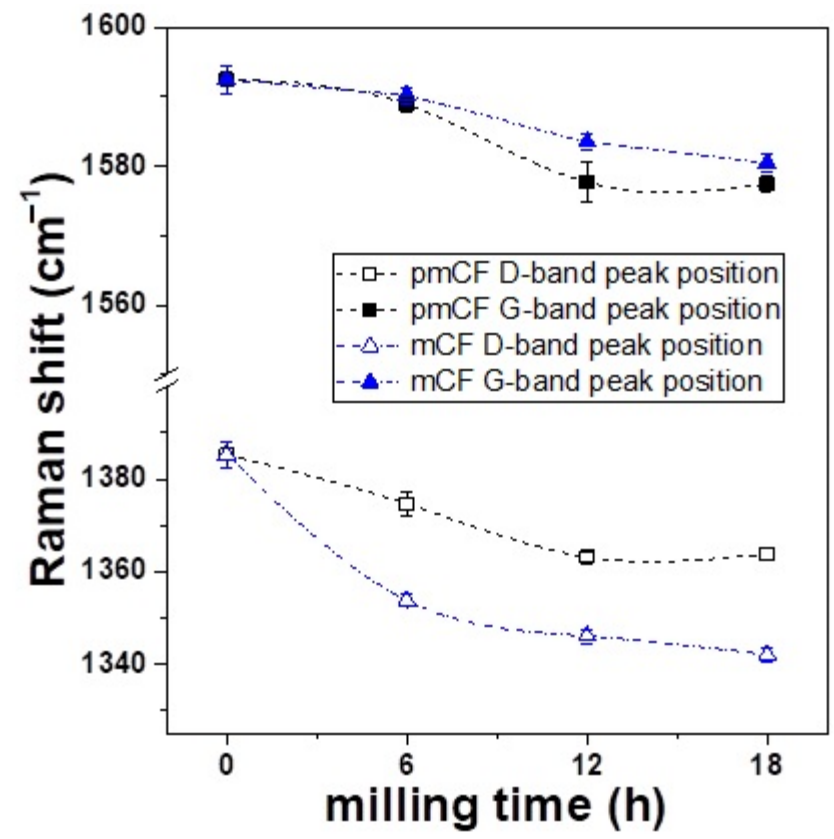

Figure 5. Peak position change of the first-order D and G bands. 
In addition, the Raman peak position in the D-band of the mCF shifted to a lower value at an earlier milling time than in the D-band of the pmCF. This is possibly due to the poor organization of carbon materials (i.e., more disorder) [22]. The change in the gradient of the D-band (peak position shift) of the $\mathrm{mCF}$ at $6 \mathrm{~h}$ of milling time was very large, but the change in gradient became similar for milling times longer than $6 \mathrm{~h}$. This suggests that the change in the gradient of the D-band was large within $6 \mathrm{~h}$ of milling time because the internal crystals were severely damaged in the early milling process. The continued ball milling process may have turned the $\mathrm{pmCF}$ into $\mathrm{mCF}$, and a similar magnitude of stress may have been applied to the ordered phase and the disordered phase. This finding may be associated with the abovementioned XRD results, which showed a drastic change in the $d_{002}$ and $L_{c}$ in the LDCC band of the sample at $6 \mathrm{~h}$ of ball milling time. These results verify that the increase in $d_{002}$ and the decrease in $L_{c}$ in the early milling process are related to the damage of the internal crystals [8].

Table 3 and Figure 6 show the $R$ and $L_{a}$ of the pmCF and mCF depending on the milling time. Figure 6a shows that the $R$ value of the desized carbon fiber was 0.84 , and the value of both the pmCF and $\mathrm{mCF}$ increased with the increase in milling time. At $18 \mathrm{~h}$ of milling time, the $R$ value of the pmCF was 0.87 and that of the mCF was 0.90 . While the $R$ value of the pmCF linearly increased with the increase in milling time, that of the mCF rapidly increased within $6 \mathrm{~h}$ and then further increased slowly.

Table 3. Analysis of peaks of mPCFs depending on milling time.

\begin{tabular}{|c|c|c|c|c|c|c|c|c|c|c|c|c|}
\hline \multirow{3}{*}{ Time (h) } & \multicolumn{6}{|c|}{ pmCF } & \multicolumn{6}{|c|}{$\mathrm{mCF}$} \\
\hline & \multicolumn{2}{|c|}{ Peak Position } & \multicolumn{2}{|c|}{ Peak Intensity } & \multirow{2}{*}{$\underset{\left(=I_{D} / I_{G}\right)}{R}$} & \multirow{2}{*}{$L_{a}(\AA ̊)$} & \multicolumn{2}{|c|}{ Peak Position } & \multicolumn{2}{|c|}{ Peak Intensity } & \multirow{2}{*}{$\underset{\left(=I_{D} / I_{G}\right)}{R}$} & \multirow{2}{*}{$L_{a}(\AA)$} \\
\hline & D-Band & G-Band & D-Band & G-Band & & & D-Band & G-Band & D-Band & G-Band & & \\
\hline 0 & 1385.3 & 1592.5 & 2265.4 & 2706.6 & 0.84 & 52.57 & & & & & & \\
\hline 6 & 1374.7 & 1588.9 & 3145.4 & 3719.2 & 0.85 & 52.03 & 1353.8 & 1590.2 & 2414.8 & 2744.8 & 0.88 & 50.01 \\
\hline 12 & 1363.2 & 1577.7 & 2665.5 & 3102.3 & 0.86 & 51.21 & 1346.1 & 1583.5 & 1328.4 & 1480.1 & 0.89 & 49.02 \\
\hline 18 & 1363.9 & 1577.4 & 3870.1 & 4474.6 & 0.87 & 50.87 & 1342.1 & 1580.5 & 1185.0 & 1310.7 & 0.90 & 48.67 \\
\hline
\end{tabular}

The Raman crystallite size is expressed as $L_{a}=(C / R)$, and the most appropriate value of the constant $C$ was 44 in comparison with the $L_{a}$ value from the XRD data. Therefore, we used $L_{a}=(44 / R)$ for the calculation in the present study. Figure $6 \mathrm{~b}$ shows that the Raman crystallite size $L_{a}$ decreased from the initial value of $52.57 \AA$ to $50.87 \AA$ in pmCF, and to $48.67 \AA$ in $\mathrm{mCF}$ at $18 \mathrm{~h}$ of milling time. The $L_{a}$ of pmCF slowly decreased, while that of the $\mathrm{mCF}$ rapidly decreased within $6 \mathrm{~h}$ and then slowly decreased similar to the pmCF.

Figure 7 compares the $L_{a}$ values obtained from XRD with those obtained from Raman spectroscopy. The Raman $L_{a}$ value was similar to the XRD $L_{a}$ value during the early stage of the milling process. At $12 \mathrm{~h}$ of milling time, the $L_{a}$ value was different between the Raman data and the XRD data. The difference may be due to the broken pieces of the pmCF that still remained even after $12 \mathrm{~h}$ of milling time, as can be observed from the SEM images.

Since Raman spectroscopy is limited to the surface of the samples, the rate of the $L_{a}$ decrease was slower in the larger pmCF samples than in the $\mathrm{mCF}$ samples. However, the crystallinity gradually decreased in both samples as the milling process continued.

By contrast, the XRD data were obtained from not only the surface of the $\mathrm{mCF}$ and pmCF samples but also their entire particles, including the inside. Therefore, the XRD measurement data may have been affected by the presence of the considerable volume of pmCF particles that remained, even after $18 \mathrm{~h}$ of milling time. 


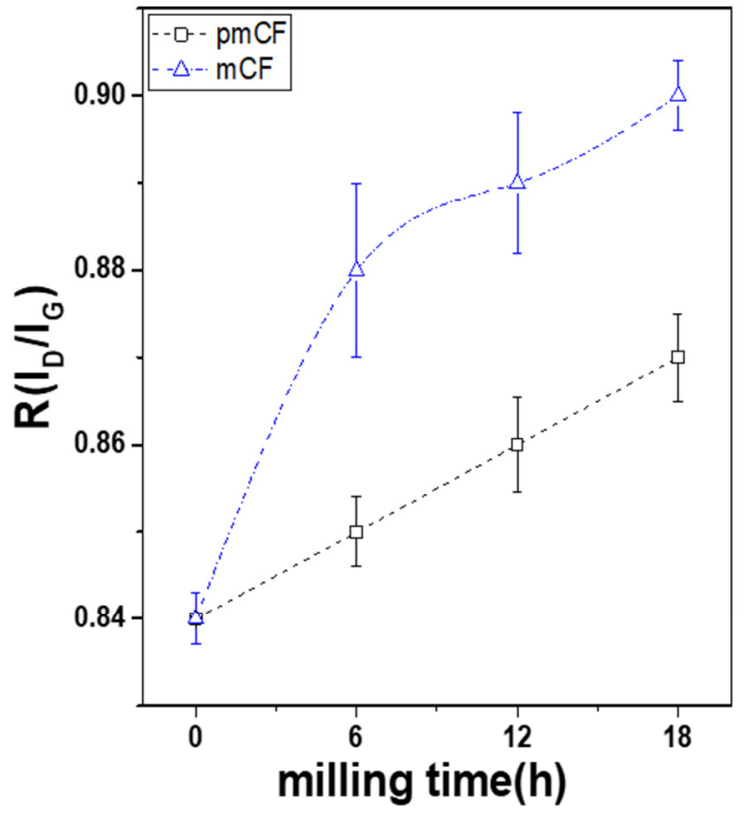

(a)

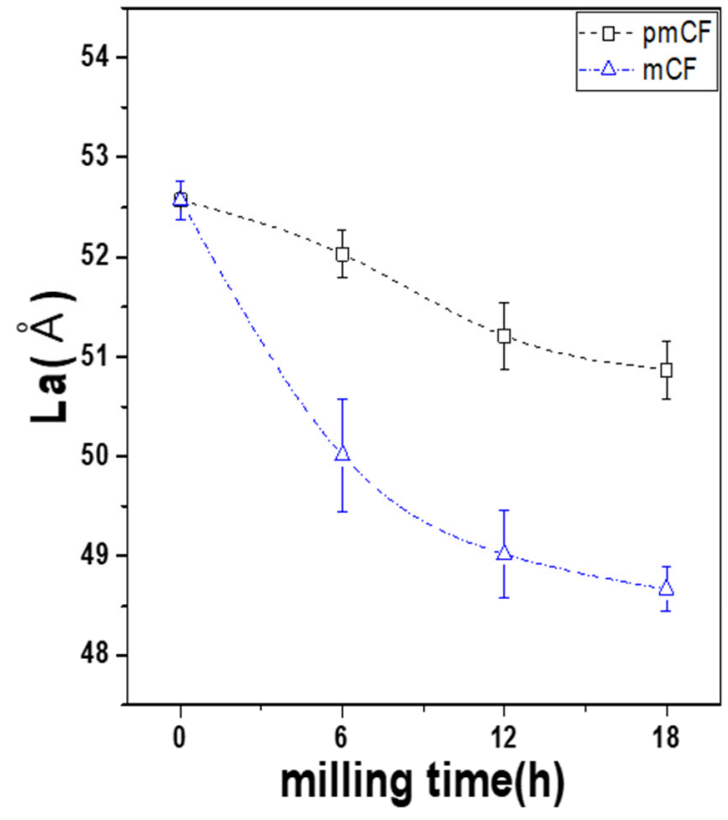

(b)

Figure 6. Raman spectroscopic results of mPCFs depending on milling time. (a) $R$ and (b) $L_{a}$.

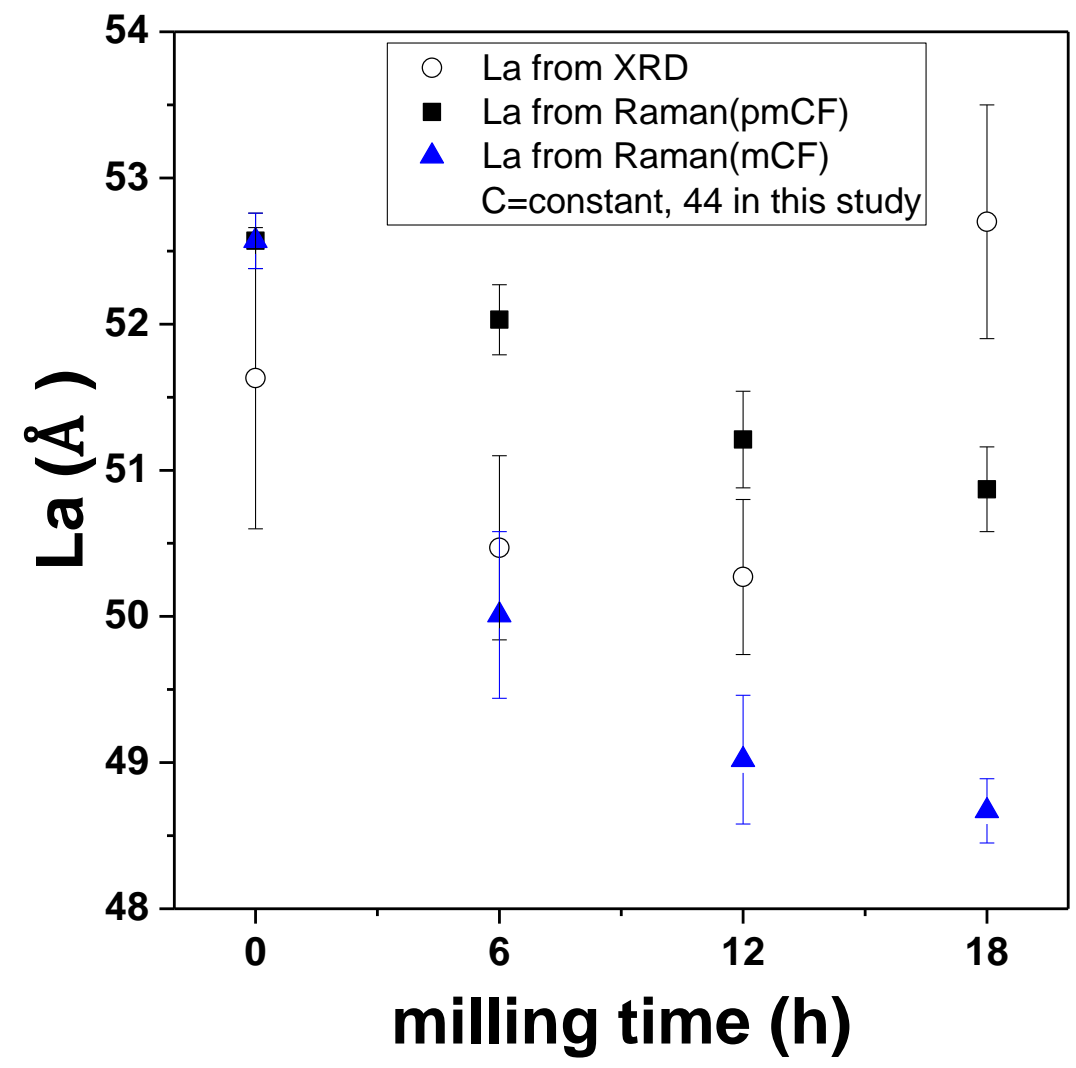

Figure 7. Correlation of $L_{a}$ values from Raman and XRD results.

Assuming that the increase in the $L_{a}$ at the milling times of $12 \mathrm{~h}$ and $18 \mathrm{~h}$ is because of a change inside the pmCF particles (XRD results), the growth of the $L_{a}$ in the pmCF particles may be due to the ball milling process. In other words, the crystal growth may have been caused by mechanical stress. Obviously, milling gradually reduces the crystallinity of fiber surface and pulverizes fibers. Our finding about the change inside the 
particles by mechanical stress in a milling process has never been reported in the field of carbon materials.

A similar example was found in mechanical alloying, that occurs in the pulverization of a metallic material. P. S. Gilman et al. $[23,24]$ studied the mechanical alloying of metal powder and reported that the ball-powder-ball collision affects the particles. They explained that as the particles are flattened and overlapped during ball milling, atomically clean interfaces come into close contact with one another to form composite particles, as in cold welding. They referred to the formation of the composite particles as mechanical alloying, which is a representative example of the homogenizing and refining of particles by mechanical stress. M. Mhadhbi et al. [21] also reported that crystallite size was increased by the mechanical alloying of Fe and Al.

Such mechanical alloying may be applied to carbon fibers impacted by balls in a milling process. The crystalline structure of carbon materials is composed of layers bonded by the weak van der Walls force, and their bonds may be easily broken by the impact of the balls. However, the lattices have strong $\mathrm{sp}^{2}$ covalent bonds, which are relatively resistant to the balls' impact. Although the fiber surface is easily broken and pulverized by the balls, the unbroken internal part of the fiber may undergo mechanical alloying by the mechanical stress (mPCFs at $18 \mathrm{~h}$ of milling time) and grow into fine crystal grains.

Therefore, in the present study, the internal part of the mPCFs fiber may have undergone 'mechanical alloying' by the long-term ball-fiber collisions (mechanical stress) during the ball milling process, and the La may have been increased after $18 \mathrm{~h}$ of milling as a result (XRD results).

\subsection{TEM}

Figure 8 shows the diffraction patterns and the TEM lattice images of the mPCFs depending on the milling time. The images were obtained from at least three randomly selected points that were considered most general. As shown in Figure 8a, the (002) diffraction pattern was difficult to observe accurately due to the strong light of the transmitted beam; thus, the TEM lattice images were very difficult to obtain. Since carbon fibers laminated in parallel in the A-B-A-B form has a turbostratic structure rather than a three-dimensional graphite structure, the (10l) and (11l) diffraction patterns are not clearly distinguished.

Figure $8 \mathrm{~b}$ shows that the (002) diffraction pattern of the mPCFs at $6 \mathrm{~h}$ of milling time was not as distinctive as that of the desized carbon fiber, indicating that crystallinity had decreased in comparison with the starting fiber materials. Figure $8 \mathrm{~b}$ shows some crystallites that were bent by the ball impact and some adjacent crystallite layers that were disconnected (white arrows).

Figure $8 \mathrm{c}$ shows that the (002) diffraction pattern of the fibers became vaguer at $12 \mathrm{~h}$ of ball milling. The vaguer (11l) diffraction pattern indicates that the lamination of the crystallites became worse. The disconnection between adjacent crystallite layers, already found at $6 \mathrm{~h}$ of milling time, was more outstanding at $18 \mathrm{~h}$ of milling time.

Figure $8 \mathrm{~d}$ shows the diffraction pattern of the fiber that was milled for $18 \mathrm{~h}$, and it was more distinctive than that of other fiber samples. The more distinctive diffraction pattern suggests that higher crystallinity resulted from the better organization of the external crystallite layers.

The lattice images and diffraction patterns show that the crystallites became disordered at $12 \mathrm{~h}$ of ball milling time, but the crystals were again developed at $18 \mathrm{~h}$ of milling time. This is consistent with the XRD results that the $L_{a}$ value decreased at $12 \mathrm{~h}$ of milling time and then increased at $18 \mathrm{~h}$. 

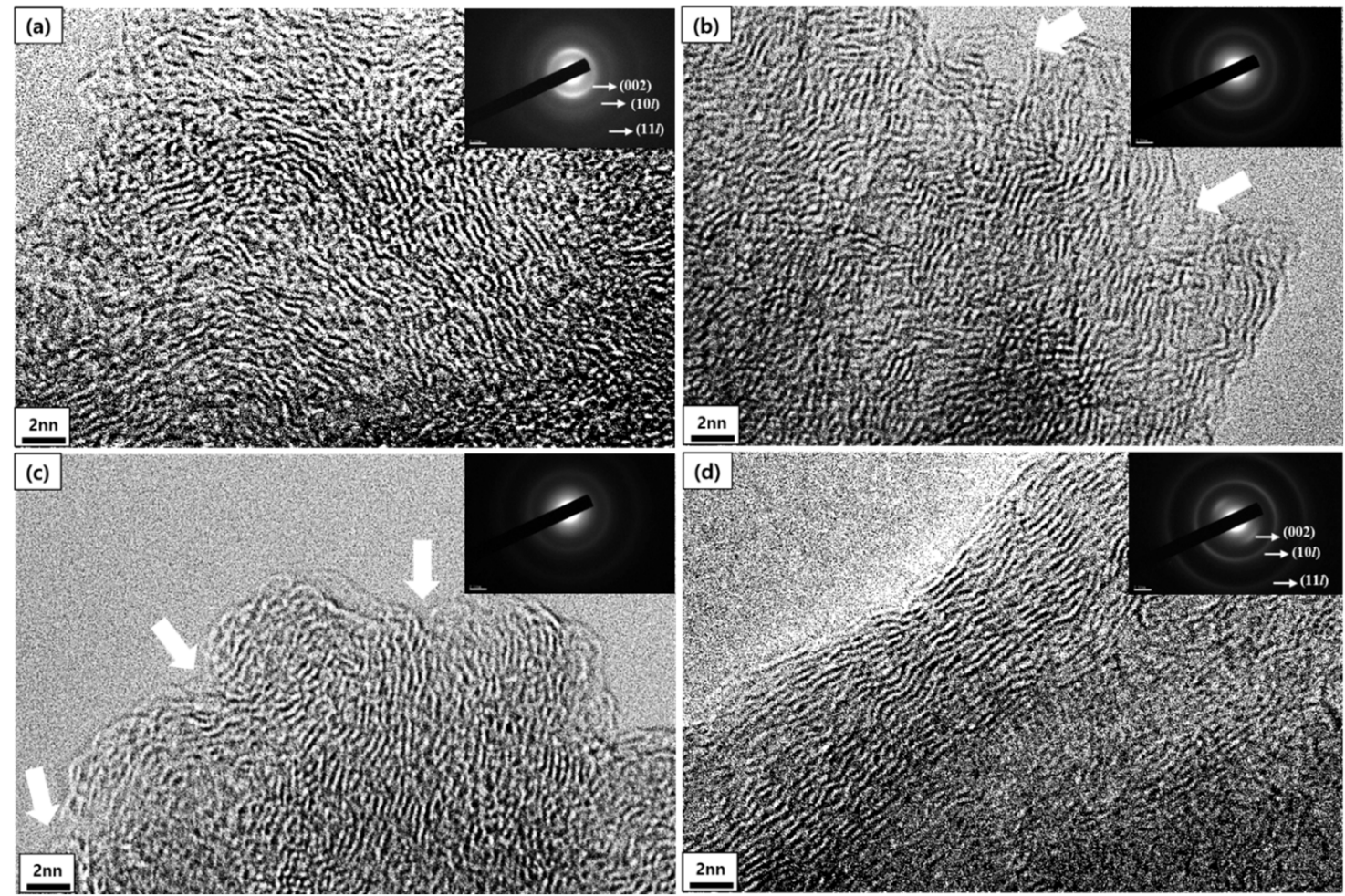

Figure 8. TEM lattice image and diffraction pattern $(\times 800 \mathrm{k})$ of mPCFs depending on milling time: (a) desized carbon fiber; ball milling times of (b) $6 \mathrm{~h}$ mPCFs, (c) $12 \mathrm{~h}$ mPCFs, and (d) $18 \mathrm{~h} \mathrm{mPCFs}$.

\section{Conclusions}

We investigated the effect of ball milling time on fiber structure in the preparation of mPCFs and obtained the following conclusions.

\section{Structural Analysis by XRD}

The crystallite size, $L_{a}$, obtained from the XRD spectra decreased at $12 \mathrm{~h}$ of ball milling time and then drastically increased at $18 \mathrm{~h}$. This suggests that the $L_{a}$ decreased during the early stage of the milling process as the fibrous surface was broken and then, as the milling time was further increased, $L_{a}$ was increased by internal crystal growth induced by the impact energy from the balls, as in the case of mechanical alloying.

2. Structural Analysis by Raman Spectroscopy

The Raman data showed that the disorder in the pmCF and mCF samples gradually increased, and $L_{a}$ decreased as the milling time was increased. Since Raman spectroscopy analyzes the crystallinity on the fibrous surface, the observed decrease in the $L_{a}$ value may be due to the continuous breaking of the fibrous surface by the ball milling. The crystallinity decreased more in the $\mathrm{mCF}$ samples, which were pulverized more. In addition, the calculation of the $L_{a}$ showed that the appropriate value of the constant $C$ was approximately 44 for the mPCFs.

\section{Structural Analysis by TEM}

The lattice images and diffraction patterns showed that the crystallites became disordered at $12 \mathrm{~h}$ of milling time, and then crystals developed again at $18 \mathrm{~h}$ of milling time. This finding is consistent with the trend in $L_{a}$ found in the XRD results. Although accurately distinguishing the $\mathrm{pmCF}$ from the $\mathrm{mCF}$ may not be possible due to limitations, separate sampling of the pmCF and $\mathrm{mCF}$ may be a good method for analyzing the structures. 
Based on this study, it is suggested that mCF can be used as an anode material for batteries and as a filler material for artificial graphite blocks in the future. In particular, it is expected to be useful for inducing the development of crystallinity on the surface of $\mathrm{mCF}$ with a longer milling time from the TEM results.

Author Contributions: Conceptualization, S.-H.L. and J.-S.R.; methodology, J.-S.R.; software, S.-H.L.; validation, S.-H.L., S.-M.L. and J.-S.R.; formal analysis, S.-H.L.; investigation, J.S.R.; resources, J.S.R.; data curation, S.-H.L.; writing — original draft preparation, S.-H.L.; writing—review and editing, J.-S.R.; visualization, S.-H.L.; supervision, J.-S.R.; project administration, J.-S.R.; funding acquisition, J.-S.R. All authors have read and agreed to the published version of the manuscript.

Funding: This research was funded by the National Research Foundation of Korea grant funded by the Korea Government, grant number NRF-2018R1A6A1A03025761.

Institutional Review Board Statement: Not applicable.

Informed Consent Statement: Not applicable.

Data Availability Statement: Data available on request from the corresponding authors due to restrictions eg privacy or ethical.

Conflicts of Interest: The authors declare no conflict of interest.

\section{References}

1. Wu, C.; Feng, P.; Bai, Y.; Lu, Y. Epoxy enhanced by recycled milled carbon fibres in adhesively-bonded CFRP for structural strengthening. Polymers 2014, 6, 76-92. [CrossRef]

2. Endo, M.; Kim, C.; Karaki, T.; Kasai, T.; Matthews, M.J.; Brown, S.D.M.; Dresselhaus, M.S.; Tamaki, T.; Nishimura, Y. Structural characterization of milled mesophase pitch-based carbon fibers. Carbon 1998, 36, 1633-1641. [CrossRef]

3. Thongruang, W.; Spontak, R.J.; Balik, C.M. Correlated electrical conductivity and mechanical property analysis of high-density polyethylene filled with graphite and carbon fiber. Polymer 2002, 43, 2279-2286. [CrossRef]

4. Ozkan, C.; Karsli, N.G.; Aytac, A.; Deniz, V. Short carbon fiber reinforced polycarbonate composites: Effects of different sizing materials. Compos. Part B 2014, 62, 230-235. [CrossRef]

5. Zakaria, M.Y.; Sulong, A.B.; Sahari, J.; Suherman, H. Effect of the addition of milled carbon fiber as a secondary filler on the electrical conductivity of graphite/epoxy composites for electrical conductive material. Compos. Part B 2015, 83, 75-80. [CrossRef]

6. Kasgoz, A.; Akin, D.; Durmus, A. Rheological and electrical properties of carbon black and carbon fiber filled cyclic olefin copolymer composites. Compos. Part B 2014, 62, 113-120. [CrossRef]

7. Wang, C.; Li, K.Z.; Li, H.J.; Jiao, G.S.; Lu, J.; Hou, D.S. Effect of carbon fiber dispersion on the mechanical properties of carbon fiber-reinforced cement-based composites. Mater. Sci. Eng. A 2008, 487, 52-57. [CrossRef]

8. Mathur, R.B.; Dhakate, S.R.; Gupta, D.K.; Dhami, T.L.; Aggarwal, R.K. Effect of different carbon fillers on the properties of graphite composite bipolar plate. J. Mater. Process. Tech. 2008, 203, 184-192. [CrossRef]

9. Tuinstra, F.; Koenig, J.L. Raman Spectrum of Graphite. J. Chem. Phys. 1970, 53, 1126-1130. [CrossRef]

10. Lespade, P.; Marchand, A.; Couzi, M.; Cruege, F. Caracterisation de materiaux carbones par microspectrometrie Raman. Carbon 1984, 22, 375-385. [CrossRef]

11. Nikiel, L.; Jagodzinski, P.W. Raman spectroscopic characterization of graphites: A re-evaluation of spectra/ structure correlation. Carbon 1993, 31, 1313-1317. [CrossRef]

12. Jawhari, T.; Roid, A.; Casado, J. Raman spectroscopic characterization of some commercially available carbon black materials. Carbon 1995, 33, 1561-1565. [CrossRef]

13. Lee, S.H.; Kang, D.S.; Lee, S.M.; Roh, J.S. X-ray diffraction analysis of the effect of ball milling time on crystallinity of milled polyacrylonitrile-based carbon fiber. Carbon Lett. 2018, 26, 11-17.

14. Kang, D.S.; Lee, S.M.; Lee, S.H.; Roh, J.S. X-ray diffraction analysis of the crystallinity of phenolic resin-derived carbon as a function of the heating rate during the carbonization process. Carbon Lett. 2018, 27, 108-111.

15. Holm, R. Electric Contacts: Theory and Applications, 4th ed.; Springer: Berlin/Heidelberg, Germany, 1967.

16. Braunovic, M.; Konchits, V.; Myshkin, N. Electric Contacts: Fundamentals, Application and Technology; CRC Press: London, UK, 2007.

17. Cuesta, A.; Dhamelincourt, P.; Laureyns, J.; Alonso, A.M.; Tascon, J.M.D. Raman microprobe studies on carbon materials. Carbon 1994, 32, 1523-1532. [CrossRef]

18. Knight, D.S.; White, W.B. Characterization of diamond films by Raman spectroscopy. J. Mater. Res. 1989, 4, 385-393. [CrossRef]

19. Roh, J.S. Structural study of the activated carbon fiber using laser Raman spectroscopy. Carbon Lett. 2008, 9, 127-130. [CrossRef]

20. Lee, S.M.; Roh, J.S. Pore development process according to burn-off of activated carbon black with CO2 gas. Fuller. Nanotub. Carbon Nanostruct. 2020, 28, 808-814. [CrossRef]

21. Mhadhbi, M.; Khitouni, M.; Escoda, L.; Suñol, J.J.; Dammak, M. Characterization of Mechanically Alloyed Nanocrystalline Fe(Al): Crystallite Size and Dislocation Density. J. Nanomater. 2010, 2010, 712407. [CrossRef] 
22. Montes-Moran, M.A.; Young, R.J. Raman spectroscopy study of HM carbon fibres: Effect of plasma treatment on the interfacial properties of single fibre/epoxy composites Part I: Fibre characterization. Carbon 2002, 40, 845-855. [CrossRef]

23. Gilman, P.S.; Benjamin, J.S. Mechanical alloying. Ann. Rev. Mater. Sci. 1983, 13, 279-300. [CrossRef]

24. Benjamin, J.S.; Volin, T.E. Mechanical alloying. Sci. Am. 1976, 234, 40-49. [CrossRef] 